\title{
CONSTRUÇÃO DOS SABERES DOCENTES DO PROFESSOR DE GEOGRAFIA
}

\author{
Profa. Msc. Rosa Elisabete Militz Wypyczynski Martins \\ Doutoranda no Programa de Pós-Graduação em Geografia da UFRGS \\ Av. Bento Gonçalves, 9500. Prédio 43113/203 - CEP: 91501 900, Cx. P. 15019 - Porto Alegre/RS - Brasil \\ Tel:(21)33086347-rmartins@upf.br
}

\begin{abstract}
RESUMO
O presente trabalho tem por objetivo fazer uma reflexão sobre o papel da formação inicial acadêmica na construção dos saberes docentes, destacando como estes se constituem e são necessários à atuação profissional. É importante considerar que os desafios com os quais os educadores têm se deparado, com mudanças profundas na sociedade, no mundo do trabalho e na economia, têm alterado as relações estabelecidas na escola e contribuem para caracterizar novas exigências para a profissão. A escola e os modelos tradicionais de ensino estão sendo questionados, pois não dão conta de uma realidade em constante transformação. Cada vez mais, os professores se deparam com desafios e situações que lhes impossibilitam atender às especificidades do seu trabalho. Exige-se cada vez mais que o professor dê conta de um corpo de conhecimentos e saberes na sua atuação profissional. São conhecimentos que ele precisa mobilizar para transformar sua ação pedagógica. Com base em teóricos como Tardiffe e Gauthier e pesquisadores como Lana Cavalcanti e Helena C. Callai, busca-se questionar como os cursos de formação inicial de geografia têm contribuído no processo de aprendizagem profissional, na formação de sujeitos autônomos, capazes de organizar o seu trabalho e de planejar ações diante da necessidade de encontrar soluções para situações complexas da sala de aula.
\end{abstract}

Palavras-chave: formação inicial, geografia, saberes docentes.

\begin{abstract}
This paper aims to reflect on the role of academic training in the construction of teacher's knowledge, highlighting how they are and are necessary for professional practice. It is important to consider the challenges that educators have been confronted with profound changes in society in the world of work and the economy have altered the relationships established at school and help determine new requirements for the profession. The school and the traditional models of education are being questioned because they do not realize a reality in constant transformation. Increasingly, teachers are faced with challenges and situations that are impossible to meet specifics of your work. It is required more and more that the teacher becomes aware of a body of knowledge and expertise in their professional activities. They know that it needs to mobilize to transform the classroom. Based on theoretical and Tardiff and Gauthier and researchers as Lana Cavalcanti and Helena C. Callai, we seek to question how the initial training courses in geography have contributed in the process of apprenticeship, the formation of autonomous individuals, able to organize their work and to plan actions against the need to find solutions to complex situations Newsroom class.
\end{abstract}

Keywords: training, Geography, teacher's knowledge.

\section{RESUMEN}

Este trabajo tiene como objetivo reflexionar sobre el papel de la formación académica en la construcción de los conocimientos del profesor, destacando cómo están y son necesarios para la práctica profesional. Es importante tener en cuenta los retos que los educadores se han enfrentado a cambios profundos en la sociedad en el mundo del trabajo y la economía han alterado las relaciones que se establecen en la escuela y ayudar a determinar nuevas necesidades de la profesión. La escuela y los modelos tradicionales de la educación están siendo cuestionados debido a que no se dan cuenta de una realidad en constante transformación. Cada vez más, los docentes se enfrentan a retos y situaciones que son imposibles de cumplir detalles de su trabajo. Se requiere más y más que el profesor se da cuenta de un cuerpo de conocimientos y experiencia en sus actividades profesionales. Ellos saben que es necesario para movilizar a transformar el aula. Basándose en teóricos y Tardiff y Gauthier y los investigadores como Lana Cavalcanti y Helena C. Callai, buscamos a la pregunta de cómo los cursos de formación inicial en la geografía han contribuido en el proceso de aprendizaje, la formación de individuos autónomos, capaces de organizar su trabajo y planificar acciones en contra de la necesidad de encontrar soluciones a situaciones complejas de salón de clase.

Palabras Clave: formación inicial, Geografia, conocimiento del profesor.

\section{Introdução}

A preocupação em analisar o processo de formação do professor de geografia constitui uma questão ampla e complexa, indicando que este é um dos grandes desafios a serem enfrentados para o aperfeiçoamento da educação básica. Adisciplina de geografia é ministrada na escola no ensino fundamental 
e médio e tem um papel a cumprir na formação de crianças e adolescentes. Para dar conta disso, é preciso que o processo de formação desses profissionais tenha um suporte teórico capaz de referenciar a ação docente. Se há uma preocupação em definir o papel da geografia no currículo da escola básica, os objetivos, o que ensinar de geografia e com que interesses, temos de pensar a questão da formação desse professor: O que é geografia escolar para ele? Quais os desafios que acredita que enfrentará na sua prática em sala de aula? Com relação ao cotidiano da escola e dos alunos, que realidade espera encontrar? De que conhecimentos necessita para desenvolver suas atividades como docente? Enfim, o que esse futuro professor espera da formação inicial básica e qual é o papel dessa formação no processo de aprendizagem profissional.

Há algumas décadas, a educação tinha o caráter de transmissão e assimilação de saberes. Hoje, vivemos num momento importante na educação, que envolve um processo de mudanças com relação ao seu papel, visto que a construção do conhecimento deve se constituir como um meio de emancipação humana. Portanto, o conhecimento geográfico deve contribuir para a reflexão crítica e possibilitar ao educando o desenvolvimento da cidadania. O papel da escola tem de ser muito mais do que a transmissão de um saber sistematizado. É imprescindível que se contribua para formar sujeitos históricos, com autonomia e capacidade para definir o seu destino.

Os desafios da docência levam-nos ao questionamento da relação que existe entre a formação acadêmica e a atuação do professor no cotidiano da sala de aula. Existe uma complexidade de elementos que se articulam e que contribuem para o desenvolvimento da prática pedagógica. Um curso de formação de professores tem a função de suprir não apenas a demanda de profissionais em quantidade, mas, sobretudo, em qualidade, por meio de uma sólida formação teórica que lhes possibilite enfrentar as contradições que emergem da e na práxis.

Cavalcanti no artigo "A formação de professores de geografia - o lugar da prática de ensino", analisa o papel da disciplina de Didática e Prática de Ensino de Geografia na orientação do trabalho docente. Considera que, para a atuação do professor de geografia, é importante que sua formação "dê conta da construção e reconstrução dos conhecimentos geográficos fundamentais e de seu significado social" (2003, p. 201).

Pensar a formação do professor de Geografia requer que tenhamos claro o que se espera desse profissional num momento como o atual, em que o mundo se transforma tão rapidamente, e ocorrem mudanças sociais e econômicas importantes na sociedade. Como, então, encarar os desafios na busca de uma formação que seja adequada às novas necessidades?

\section{Desenvolvimento}

Os estudos e pesquisas sobre a docência, nos mais variados enfoques, assumem cada vez mais importância na literatura educacional. O interesse crescente por parte dos educadores em discutir questões que envolvem os diversos aspectos da profissão está vinculado ao fato de diversos profissionais da educação estarem enfrentando dificuldades na sua prática do dia-a-dia da sala de aula.

É importante considerar que os desafios com os quais os educadores têm se deparado, com mudanças profundas na sociedade, no mundo do trabalho e na economia, têm alterado as relações estabelecidas na escola e contribuem para caracterizar novas exigências para a profissão. A escola e os modelos tradicionais de ensino estão sendo questionados, pois não dão conta de uma realidade em constante transformação. Para Guiomar N. de Mello, "a principal questão reside no fato de haver uma significativa distância entre o perfil da escola e do professor necessário e o perfil existente para enfrentar as demandas desse novo cenário".(2004, p. 99)

Cada vez mais, os professores deparam-se com desafios e situações que lhes impossibilitam atender as especificidades do seu trabalho. Exige-se cada vez mais que o professor dê conta de um corpo de conhecimentos e saberes na sua atuação profissional. São conhecimentos que ele precisa mobilizar para transformar sua ação pedagógica. Segundo Pereira, é preciso repensar o papel do professor. 
(....) parece ser o papel do professor bem mais complexo do que a simples tarefa de transmitir o conhecimento já produzido. O professor, durante sua formação inicial ou continuada, precisa compreender o próprio processo de construção e produção de conhecimento escolar, entender as diferenças e semelhanças do processo de produção do saber científico e do saber escolar, conhecer as características da cultura escolar, saber a história da ciência e a história do ensino da ciência com que trabalha e em que pontos elas se relacionam. (Pereira, 2000, p. 47).

A complexidade de variáveis presentes no cotidiano da escola revela que não basta ao professor possuir apenas conhecimentos científicos para transmitir aos alunos. É preciso uma série de outras competências relacionadas à didática do saber ensinar, uma vez que "o saber transmitido não possui, em si mesmo nenhum valor formador: somente a atividade de transmissão lhe confere esse valor". (Tardif, 2002, p. 44).

A preocupação em analisar o processo de formação do professor de geografia constitui uma questão ampla e complexa, indicando que este é um dos grandes desafios a serem enfrentados para o aperfeiçoamento da educação básica. Adisciplina de geografia é ministrada na escola no ensino fundamental e médio e tem um papel a cumprir na formação de crianças e adolescentes. Para dar conta disso, é preciso que o processo de formação desses profissionais tenha um suporte teórico capaz de referenciar a ação docente. É fundamental que o professor esteja consciente de que

(...) ensinar já não significa transferir pacotes sucateados, nem mesmo significa meramente repassar o saber. Seu conteúdo correto é motivar o processo emancipatório com base em saber crítico, criativo, atualizado, competente. Trata-se, não de cercear, temer, controlar a competência de quem aprende, mas de abrir a chance na dimensão maior possível. Não interessa o discípulo mas o novo mestre. Entre o professor e o aluno não se estabelece apenas hierarquização verticalizada, que divide papéis pela forma do autoritarismo, mas, sobretudo, confronto dialético. Este, alimenta-se da realidade histórica formada por entidades concretas que se relacionam de modo autônomo, como sujeitos sociais plenos. (Demo, 1993, p. 153).

É nessa perspectiva que queremos pensar o ensino da geografia e analisar o processo de formação dos professores da área.

Assim, é importante conhecer e refletir sobre o processo que envolve a constituição da identidade profissional do professor, pois sua " prática é resultado do saber, do fazer e principalmente de ser, significando um compromisso consigo mesmo, com o aluno, com o conhecimento e com a sociedade e sua transformação" (Grillo, 2001, p.79).

A formação do professor necessita ser analisada na ótica de alguém que, como cidadão e sujeito social, carrega marcas do contexto sociocultural em que está inserido. Para Santos, "as estruturas são momentos ou marcos sólidos na corrente fluída da prática, e que o seu grau de fluidez só pode ser determinado em situações concretas, estando condenado a modificar-se à medida que as situações se desenrolam" (2002, p. 262). O significado que cada professor confere a sua atividade como docente está relacionado aos seus valores e a sua história de vida; seu modo de situar-se no mundo e suas representações são significativos na construção da sua identidade como educador e ajudam a configurar os saberes que estruturam a sua profissão.

As pesquisas realizadas por Maurice Tardif apontam que a prática profissional do professor não é um mero ofício de aplicação de teorias; é, sim, um espaço de produção de saberes e conhecimentos usados no seu desenvolvimento profissional e na sua emancipação. Esses saberes provêm de diferentes fontes e dão origem a um saber plural, "formado pelo amálgama, mais ou menos coerente, de saberes oriundos da formação profissional e de saberes disciplinares, curriculares e experienciais" (2002 p. 36).

Esses saberes são empregados na prática pedagógica e podem ser compreendidos da seguinte forma: os saberes oriundos da formação profissional são aqueles adquiridos durante a formação inicial e que qualificam a profissão do professor; os saberes disciplinares referem-se aos conhecimentos que são 
difundidos pela universidade, oriundos de diversos campos científicos; os saberes curriculares são aqueles presentes nos programas e currículos escolares; os saberes experenciais são os conhecimentos produzidos e validados pela experiência dos educadores no seu trabalho cotidiano.

Gauthier, com base em estudos sobre o saber docente, afirma que os professores, para desenvolverem suas atividades, necessitam de um conjunto de conhecimentos que "formam uma espécie de reservatório no qual o professor se abastece para responder a exigências específicas de sua situação concreta de ensino" (1998 p.28). Esses conhecimentos ligados ao fazer pedagógico, que constituem um desafio à profissionalização docente, constituem os saberes que são mobilizados pelo professor na sua prática. Gauthier denomina esses saberes de: saber disciplinar aquele produzido pelos pesquisadores nas diversas áreas do conhecimento, conceitos e métodos relativos a uma disciplina; saber curricular é o saber que a escola como instituição seleciona e organiza para ser ensinado nos programas/currículos escolares; saberes das ciências da educação referem-se aos saberes que todo professor adquire durante a sua formação a respeito da educação e do seu ofício; saberes da tradição pedagógica dizem respeito ao saber das aulas e estão relacionado com a representação que previamente cada professor tem da escola e serão adaptados pelo saber experiencial do dia-a-dia da prática pedagógica; saber experiencial é um saber que se limita às experiências de cada professor em sua sala de aula ao longo da sua carreira, feito de pressupostos não verificados cientificamente; saber da ação pedagógica é o saber experiencial dos professores que é testado com pesquisas realizadas em sala de aula, as quais, ao serem socializadas, podem servir de apoio e ação para outros professores.

Os saberes enfocados tanto por Tardiff quanto por Gauthier complementam-se ao enfocarem que os educadores, na sua atuação profissional, enfrentam uma gama de situações que impõem uma série de decisões relacionadas ao cotidiano da sua prática pedagógica. Então, é preciso questionar como os cursos de formação inicial de professores têm contribuído no processo de aprendizagem profissional, na formação de sujeitos autônomos, capazes de organizar o seu trabalho, de planejar ações diante da necessidade de encontrar soluções para situações complexas da sala de aula. De acordo com Leite:

É preciso assegurar que a formação de professores possibilite ao profissional docente saber lidar com o processo formativo dos alunos em suas várias dimensões, além da cognitiva, englobando a dimensão afetiva, da educação dos sentidos, da estética, da ética e dos valores emocionais. (2006, p. 69).

O curso de Geografia licenciatura da Universidade de Passo Fundo - RS caracteriza-se pela intencionalidade da formação de professores ancorada em saberes que possam responder às questões da sociedade contemporânea na perspectiva da construção do conhecimento da ciência geográfica. Além da formação geral, os acadêmicos recebem uma formação pedagógica por meio de disciplinas que possibilitam a articulação entre as dimensões teoria e prática, o conhecimento da realidade profissional e a realização das práticas de ensino (estágios), que são espaços concretos da efetivação da realidade profissional.

$\mathrm{Na}$ construção do projeto Político Pedagógico do curso houve, além dos aspectos legais, a preocupação em incorporar as mudanças paradigmáticas da geografia enquanto ciência e sua abordagem enquanto matéria de ensino; também, o compromisso de formar profissionais da educação/geografia capazes de exercer um trabalho pedagógico que possa contribuir para a autonomia e o esclarecimento dos indivíduos sobre sua condição de cidadãos, a compreensão do espaço e as relações estabelecidas nele.

O curso é estruturado em oito semestres. A partir do quarto semestre os alunos têm as disciplinas de Metodologia e Prática de Ensino em Geografia I, II, II e IV e as disciplinas de Estágio Supervisionado em Geografia I, II, II, e IV, que correspondem a espaços de monitoria, oficinas e prática no ensino fundamental e médio. São disciplinas que compõem um eixo teórico-metodológico e têm o objetivo de promover a integração e a articulação na formação do professor de geografia.

Como professora do curso nas disciplinas de Metodologia e Prática de Ensino, organizei uma atividade com os alunos do nível quatro na disciplina de Metodologia e Prática de Ensino de Geografia I no segundo semestre de 2006, com o objetivo de provocar respostas investigativas e analíticas sobre a prática 
profissional docente, pois é fundamental que se compreenda como vai se dando a aprendizagem profissional e quais os conhecimentos que precisam ser mobilizados para o desenvolvimento diário da docência. De acordo com o Projeto Político-pedagógico do curso de Geografia, essa disciplina está organizada na matriz curricular dentro do eixo "a preparação para a intervenção e para a transmissão" e tem como objetivo:

Desenvolver conteúdos pedagógicos gerais e específicos da ciência geográfica; analisar e comparar, interdisciplinarmente, as relações entre Geografia e Pedagogia enquanto ciências que balizam a preparação para a docência, bem como a Geografia enquanto disciplina escolar, a partir dos conceitos fundamentais a uma concepção de sociedade, relacionando as tendências para o ensino coerente com a atualidade. $(2004$, p. 72$)$.

A proposta da atividade foi a seguinte: após a apresentação da disciplina e uma reflexão sobre o papel da geografia, os alunos deveriam elencar os saberes/conhecimentos que eles acreditavam que um professor de geografia precisa mobilizar para sua atuação na sala de aula. É preciso salientar que, do grupo de dezessete alunos na turma, apenas três tinham experiência com docência: dois na área da geografia e um com anos iniciais.

Após um período de discussões em grupo, cada aluno(a) passou a expor o seu entendimento sobre a questão proposta. Para a maioria dos alunos, existem duas situações que os preocupam: a primeira diz respeito ao domínio dos saberes específicos da geografia; a outra está relacionada ao modo de atuar no interior da sala de aula, de enfrentar situações que podem ocorrer no dia-a-dia escolar.

Para Cavalcanti (2006), o processo de formação inicial implica a definição de um eixo de ligação entre a universidade, a escola e a geografia escolar. Isso facilitará a compreensão do movimento que ocorre no cotidiano da escola, conduzindo a que esse profissional possa articular a sua formação com o trabalho que irá desenvolver.

Com relação à docência em geografia, Cavalcanti salienta que há um processo complexo de relação entre o conhecimento acadêmico (os específicos da geografia e os didático-pedagógicos) e os conhecimentos da experiência pessoal dos professores. A articulação entre esses conhecimentos será referência para construção do seu referencial profissional.

Ao se deparar com um conteúdo a ser ensinado, o professor dispõe: de uma experiência pessoal com a aprendizagem desse conteúdo; de experiências anteriores de ensino desse conteúdo; de conhecimentos científicos sobre esses conteúdos em sua formação inicial e contínua; de livros didáticos e outros materiais de iniciação de conteúdos; de experiências e materiais didáticos produzidos por colegas; de uma estrutura de funcionamento e de encaminhamentos de formas de trabalho com o conteúdo de ensino na escola em que trabalha. (Cavalcanti, 2006, p 122-123).

Para Callai (2006), a docência em geografia requer que o profissional que irá atuar com essa ciência se aproprie de certos conceitos e questões básicas que são essenciais para o desenvolvimento do raciocínio geográfico. Estudar o espaço geográfico pressupõe o entendimento de que esse espaço é organizado pelos homens e é fruto das relações que ele estabelece com a natureza e na sua vida em sociedade. Essa compreensão será fundamental para o entendimento dos problemas que a sociedade apresenta.

O olhar que esse profissional terá para a análise geográfica está diretamente ligado a sua concepção de mundo e de sociedade. Por isso, é importante que, ao longo do processo de formação, seja construído um referencial teórico que possa dar conta dos avanços epistemológicos da ciência como um todo e do papel da geografia na escola hoje. Isso contribuirá para que a geografia escolar seja uma disciplina que possibilite a formação de sujeitos capazes de analisar e interpretar a realidade, com condições de fazer proposições que sejam adequadas à sociedade. Ainda segundo Callai: 
Portanto, formar o espírito geográfico requer o emprego de métodos de ensino, metodologias e técnicas que superem a simples transmissão de informações e que se assentam em alternativas para mobilizar o intelecto do aluno, fazendo com que ele se pergunte e não apenas espere respostas. As perguntas não vêm do nada e devem necessariamente superar o senso comum, para o que se faz necessário criar condições, dando oportunidade deter conhecimentos que considerem tanto as referências teóricas quanto as informações relativas ao mundo geral. (2006, p. 152).

Ao refletirmos sobre os saberes que envolvem o exercício profissional docente, acreditamos que, para atender o atual momento de profundas transformações, no qual a ciência passa a ser desafiada pelo paradigma da complexidade, a formação docente deve contemplar a produção de conhecimentos que contribuam para constituição de profissionais reflexivos, críticos e transformadores. A capacidade de "indagar/refletir é condição profissional por excelência do professor, a ser aprendida e exercitada ao longo de sua formação, e é essa condição que lhe vai permitir manter princípios, idéias, ideais, atitudes e conhecimentos recebidos ao longo da formação". (Giovanni, 2003, p. 208).

Um curso de formação de professores tem a função de suprir não apenas a demanda de profissionais em quantidade, mas, sobretudo em qualidade, por meio de uma sólida formação teórica que lhes possibilite enfrentar as contradições que emergem da e na práxis. Para Vesentini, um bom curso de geografia não pode concentrar-se em formar especialistas, mas "desenvolver nos alunos a capacidade de 'aprender a aprender', de pesquisar, de observar, ler e refletir, de desconfiar de clichês ou estereótipos, de ter iniciativa e capacidade próprias". (2002, p 239).

No entendimento de Francisco, a ação docente realizada como prática social possibilita que o professor se constitua como um sujeito capaz de mobilizar saberes para atuação profissional. "Se quisermos ter bons professores, teremos que formá-los como sujeitos capazes de produzir ações e saberes, conscientes de seu compromisso social e político (2006, p. 36).

O avanço de pesquisas norteadas pelo paradigma segundo o qual a reflexão sobre a prática passa a ser considerada como uma nova perspectiva para formação de professores contribui para o desenvolvimento profissional e pessoal. António Nóvoa considera que a formação numa "perspectiva crítico-reflexiva, que forneça aos professores os meios de um pensamento autônomo e que facilite as dinâmicas de autoformação participada", propicia condições para a construção da identidade profissional. (1997, p. 25).

Lana Cavalcanti, ao referir-se à formação do professor de geografia nessa mesma perspectiva, destaca:

A formação de professores de geografia, na concepção de profissional crítico-reflexivo, deve ser uma formação consistente, contínua, que procure desenvolver uma relação dialética ensino-pesquisa, teoriaprática. Trata-se de uma formação crítica e aberta à possibilidade da discussão sobre o papel da geografia na formação geral dos cidadãos, sobre as diferentes concepções de ciência geográfica, sobre o papel pedagógico da geografia escolar. (2002, p. 21).

Os desafios que o docente enfrenta no cotidiano da escola são os mais variados, pois muitas situações demandam tomar atitudes e praticar ações que nem sempre são previsíveis. Essa realidade, às vezes, inibe ou deixa inseguros os acadêmicos e futuros professores que manifestam em suas falas os seus "medos" em enfrentar o dia-a-dia da sala de aula, de não saberem administrar conflitos, e, ao mesmo tempo, fazer como que a relação professor-aluno contribua positivamente no desenvolvimento do processo ensino aprendizagem.

A questão da indisciplina na escola e, consequentemente, na sala de aula é uma realidade que muitos acadêmicos em estágio ou professores iniciantes se deparam ao chegar na escola. Esta queixa bastante comum nos dias de hoje, interfere na relação pedagógica entre professor-aluno e prejudica a condução da aula e a aprendizagem. Isso não significa que os alunos devam ter um comportamento passivo e silencioso, ao contrário, o ato pedagógico necessita de uma relação dialética e participativa, pois é um "momento do emergir das falas, do movimento, da rebeldia, da oposição, da ânsia de descobrir e construir juntos, professor e alunos”. (Passos, 1996, p.118). 
As relações de poder são imanentes ao sistema educacional, pois as escolas são organizadas segundo estruturas burocratizadas e hierarquizadas; nelas, os conflitos e as divergências fazem parte do seu cotidiano. O que não podemos é confundir autoridade com autoritarismo, que representa controle e submissão dos alunos. Também não podemos desvalorizar o papel do educador para que ele não perca sua autoridade e o seu trabalho caia no laissez-faire.

O grande desafio da escola é ter uma prática educativa democrática e não se eximir de sua tarefa no que se refere à disciplina. A escola e os educadores precisam ter propostas pedagógicas claras e adequadas às necessidades e realidade dos seus alunos. Uma prática baseada em regras claras - respeito, colaboração, solidariedade - e em aulas bem preparadas, com seleção de conteúdos e estratégias metodológicas que contribuam para que os alunos se interessem pelos temas abordados em sala de aula, contribuirá para que a relação professor-aluno seja tranqüila e aconteça num clima de respeito. Rego esclarece:

A vida em sociedade pressupõe a criação e o cumprimento de regras e preceitos capazes de nortear as relações, possibilitar o diálogo, a cooperação e a troca entre membros deste grupo social (sobretudo numa sociedade complexa como a nossa). A escola, por sua vez, também precisa de regras e normas orientadas do seu funcionamento e da convivência entre os diferentes elementos que nela atuam. Nesse sentido, as normas deixam de ser vistas apenas como prescrições castradoras, e passam a ser compreendidas como condição necessária ao convívio social. (1996, p 86).

\section{Considerações Finais}

Como professora que trabalha com formação docente e pesquisadora da área de geografia, entendo que é necessário (re)pensar a formação do professor de geografia para que contribua, de forma eficiente, com o desenvolvimento da sociedade através do processo de formação do ser humano. Um dos propósitos básicos da formação universitária consiste em oferecer aos futuros profissionais da educação uma formação adequada, que integre as possibilidades de desenvolvimentos cognitivo, socioafetivo e técnico, isto é, conhecimentos inerentes à profissionalização docente, que possibilitem a integração entre a teoria e a prática. É importante que se discuta que é a realidade que envolve os cursos de formação de professores de geografia? Como são organizados e o que priorizam na formação deste profissional?

A melhoria da qualidade do ensino está relacionada à qualidade da formação dos professores, pois, como agentes formadores de crianças e adolescentes, têm um papel fundamental a desempenhar no seu espaço profissional. Este papel pressupõe que eles procurem "cultivar um espírito de crítica e respeito pela dignidade humana e que sejam capazes de associar questões pessoais e sociais em torno do projeto pedagógico de ajudar os alunos a se tornarem cidadãos críticos e ativos" (Giroux, 1983, p. 102).

A geografia é uma ciência que tem como objeto central o estudo do espaço e as relações que se estabelecem na sua formação. A compreensão das dinâmicas existentes nesse espaço, onde o homem por meio das relações de trabalho, apropria-se da natureza e modifica-a, é premissa básica do seu ensino. Tendo em vista esse papel importante da geografia, é fundamental ter claro o que é ser professor de geografia nos dias atuais. Esse profissional deve dominar referências que lhe permitam o desenvolvimento de um pensar autônomo, para que possa organizar seus saberes na produção de conhecimento que mobilizará na sua prática docente. Assim, terá condições de organizar suas propostas de trabalho e de mediar todas as etapas do processo de ensino e aprendizagem em sala de aula.

A educação escolar tem um papel essencial no aperfeiçoamento do ser humano e no desenvolvimento da sociedade. Como um mecanismo que favorece a intervenção no processo de transformação social, pode contribuir para o avanço no processo de inclusão e a minimização dos efeitos da pobreza, da submissão e da opressão. Isso pressupõe que se faça uma opção no pensar e agir no espaço educativo na busca de um projeto político-pedagógico que tenha identidade com as classes menos privilegiadas da sociedade. 
Não tenho, aqui, a pretensão de apresentar verdades absolutas, mas, sim, busco encontrar caminhos que possam contribuir na busca de alternativas à formação do profissional da geografia. Há toda uma caminhada a percorrer, permeada de dúvidas e incertezas. Seguindo o que diz Paulo Freire, é preciso ousar sem se deixar paralisar pelo medo. Se não comandamos o medo, deixamos de arriscar e não criamos nada. "Sem arriscar, ... não há possibilidade de existir" (1986, p. 76). É necessário acreditar que esse caminho pode ser percorrido mesmo com todas as dificuldades que nele se apresentam.

\section{Referência Bibliográfica}

ALMEIDA, R. D. Ensinar geografia para quem vive num outro mundo. In: ENCONTRO NACIONAL DE PRÁTICA DE ENSINO EM GEOGRAFIA. Nº 5. Anais: Belo Horizonte, PUC/MG, 1999.

AZAMBUJA, Leonardo D. de; CALLAI, Helena C. A licenciatura de geografia e a articulação com a educação básica. In: CASTROGIOVANI, Antonio C et al. Geografia em sala de aula: práticas e reflexões. 4. ed. Porto Alegre: Editora da UFRGS, 2003.

CALLAI, Helena C. A articulação teoria-prática na formação do professor de geografia. In: SILVA, Aida Maria M. et. al. Educação formal e não formal, processos formativos e saberes pedagógicos: desafios para inclusão social. Encontro Nacional de Didática e Prática de Ensino. Recife: ENDIPE, 2006. p. 143161.

CAVALCANTI, Lana de Souza. A formação de professores de geografia - o lugar da prática de ensino. In: TIBALLI, Eliandra F. Arantes; CHAVES, Sandramara Matias (Org.). Concepções e práticas em formação de professores. Rio de Janeiro: DP\&A, 2003. p. 189-206

CAVALCANTI, Lana de Souza. Geografia e práticas de ensino. Goiânia: Aletrnativa, 2002.

CAVALCANTI, Lana de Souza. Geografia escolar na formação e prática docentes: o professor e seu conhecimento geográfico. In: SILVA, Aida Maria M. et. al. Educação formal e não formal, processos formativos e saberes pedagógicos: desafios para inclusão social. Encontro Nacional de Didática e Prática de Ensino. Recife: ENDIPE, 2006. p. 109 - 126.

DEMO, Pedro. Desafios modernos da educação. Petrópolis: Vozes, 1993.

FRANCISCO, Maria Amélia S. Saberes Pedagógicos e Prática Docente. In: SILVA, Aida Maria M. et. al. Educação formal e não formal, processos formativos e saberes pedagógicos: desafios para inclusão social. Encontro Nacional de Didática e Prática de Ensino. Recife: ENDIPE, 2006. p. 27- 49.

GAUTHIER, Clermont et al. Por uma teoria da pedagogia: pesquisas contemporâneas sobra o saber docente. Ijuí: ed. UNIJUI, 1998.

GIOVANNI, Luciana Maria. O ambiente escolar de formação continuada. In: TIBALLI, Eliandra F. A.; CHAVES, Sandramara M. (Orgs.) Concepções e práticas em formação de professores: diferentes olhares. Rio de Janeiro: DP\&A, 2003.

GIROUX, Henri. Pedagogia radical.São Paulo: Cortez, 1983.

GRILlo, Marlene C. O Professor e a Docência. In: ENRICONE, Délcia (Orgs). Ser Professor. Porto Alegre. EDIPUCRS, 2001.

HURTADO, Nuñes Carlos. Comunicação e educação popular: educar para transformar, transformar para educar. Petrópolis: Vozes, 1992.

LEITE, YoshieUssami F. Olugar das práticas pedagógicas na formação dos professores. In: SILVA, Aida Maria M. et. al. Educação formal e não formal, processos formativos e saberes pedagógicos: desafios para inclusão social. Encontro Nacional de Didática e Prática de Ensino. Recife: ENDIPE, 2006. p. 65- 81. LÜDKE, Menga; ANDRÉ, Marli E. D. A Pesquisa em educação: abordagens qualitativas. São Paulo: EPU, 1986.

MARTINS, Rosa E. M. W. O ensino da geografia em questão: um olhar sobre o ensino médio. Dissertação (Mestrado). Passo Fundo: UPF, 2004.

MELLO, Guiomar Namo de. Educação escolar brasileira: o que trouxemos para o século XXI. Porto Alegre: Artmed, 2004. 
NÓVOA, António. Formação de professores e profissão docente. In: NÓVOA, António. Os professores e a sua formação. $3^{\mathrm{a}} \mathrm{ed}$. Lisboa: Dom Quixote, 1997.

PASSOS, Laurizete Ferragut. A indisciplina e o cotidiano escolar: novas abordagens, novos significados. In: AQUINO, Julio G. (org.). Indisciplina na escola: alternativas teóricas e práticas. São Paulo: Summus, 1996. p. 117- 127.

PEREIRA, Júlio Emílio Diniz. Formação de professores: pesquisas, representações e poder. Belo Horizonte: Autêntica, 2000.

REGO, Teresa Cristina R. A indisciplina e o processo educativo: uma análise na perspectiva Vygotskiana. In: AQUINO, Julio G. (org.). Indisciplina na escola: alternativas teóricas e práticas. São Paulo: Summus, 1996. p. $83-101$.

SANTOS, Boaventura de Souza. A crítica da razão indolente: contra o desperdício da experiência. 4. ed. São Paulo: Cortez, 2002. v. 1.

SHOR, I.; FREIRE, P. Medo e ousadia: o cotidiano do professor. 10ª ed. Rio de janeiro: Paz e Terra, 1986. TARDIF, Maurice. Saberes docentes e formação profissional. Petrópolis, RJ: Vozes, 2002.

VESENTINI, José W. A formação do professor de geografia - algumas reflexões. In: PONTUSCHKA, Nídia Nacib; OLIVEIRA, Ariovaldo Umbelino. Geografia em perspectiva: ensino e pesquisa. São Paulo: Contexto, 2002.

Trabalho enviado em março de 2009

Trabalho aceito em agosto de 2009 